\title{
Recent Advances in Molecular Diagnostics and Treatment of Heart Muscle Diseases
}

\author{
—From Biopsy-Focused to Systemic Diagnostics
}

\author{
Dirk Lassner $^{1 * \#}$, Christine Sabine Siegismund $^{1 *}$, Jenny Stehr ${ }^{1}$, Maria Rohde $^{1}$, Felicitas Escher $^{1,2}$, \\ Carsten Tschöpe $^{2}$, Ulrich Michael Gross ${ }^{1}$, Uwe Kühl ${ }^{1,2}$, Heinz-Peter Schultheiss ${ }^{2}$ \\ ${ }^{1}$ Institute of Cardiac Diagnostics and Therapy, Berlin, Germany; ${ }^{2}$ Department of Cardiology and Pneumonology, Charité-Univer- \\ sityhospital Berlin, Campus Benjamin Franklin, Berlin, Germany. \\ Email: "info@ikdt.de
}

Received March $6^{\text {th }}, 2013$; revised April 10 $0^{\text {th }}, 2013$; accepted May $5^{\text {th }}, 2013$

Copyright (C) 2013 Dirk Lassner et al. This is an open access article distributed under the Creative Commons Attribution License, which permits unrestricted use, distribution, and reproduction in any medium, provided the original work is properly cited.

\begin{abstract}
Cardiomyopathies are acute or chronic disorders of myocardium. Diagnostic characterization of disease entities demands endomyocardial biopsy analyses with histological, immunohistochemical and molecular biological tissue evaluations to establish a final diagnosis. Only such biopsy-based information allows so far a specific treatment of distinct cardiomyopathy subgroups. In order to reduce sampling error, tissue specimens have to be obtained and analyzed to get clinically relevant data for specific treatment options. Specific gene expression and microRNA (miRNAs) profiles as well as genetic markers add additional valuable information which not only reduce the sampling error but also improve patient management. Advantages of such biomarkers result from their general expression within the entire altered myocardium. Thus, obtained information does not depend on small tissue areas reached by biopsy. This very fact allows prediction of a myocardial infection even in virus-negative areas adjoining positive biopsy specimen. The combination of multiple deregulated miRNAs or genes into one disease specific diagnostic profile demands the integration of new profiling technologies in the routine workflows of cardiological laboratories. In future, multiplex approaches allowing rapid and absolutely reliable identification of inflammatory or virally-induced myocardial diseases will replace singleplex methods such as direct detection of viral genomes in one single biopsy. miRNAs are stable biomarkers which are not only detectable in tissue samples but also in body fluids. Consequently, the determination of distinct miRNA patterns in e.g. peripheral blood samples will provide a systemic diagnostic approach for the characterization of distinct cardiomyopathies by means of non-invasive methods. This will reduce the number of undiagnosed patients who have to undergo endomyocardial biopsy for final confirmation of their myocardial complaints. The resulting molecular diagnostics will pave the way from biopsy focused interpretation to systemic analysis of cardiomyopathies. To reach this goal, the set-up of modern diagnostics harks back to the broad portfolio of high-end analytical techniques and tools.
\end{abstract}

Keywords: Biomarker; Cardiomyopathy; Endomyocardial Biopsy; Microrna; Systemic Diagnostics

\section{Introduction}

Cardiovascular diseases constitute the most common cause of death in Western European Countries. According to surveys of the European Society of Cardiology (ESC) 12 million European patients are suffering from heart failure, including two million with non-ischemic dilated cardiomyopathy (DCM). Although myocarditis and inflammatory cardiomyopathy may result from virtually any infectious agent or be a part of an underlying

\footnotetext{
*The first 2 authors contributed equally to this work.

${ }^{\#}$ Corresponding author.
}

inflammatory or autoimmune process, viral infections and the antiviral immune responses are considered the most frequent causes [1-3].

Myocarditis and inflammatory cardiomyopathy have a wide ranging clinical presentation, contributing to the difficulties in clinical diagnosis and classification. In acute disease, the clinical presentation can range from asymptomatic ECG or echocardiographic abnormalities, to infarct-like presentation, to symptoms of cardiac dysfunction, arrhythmias or heart failure and to hemodynamic collapse. In contrast, the presenting symptoms in sub-acute myocarditis and inflammatory cardiomyopathy 
are more subtle and insidious, often with dilated cardiomyopathy, heart failure and arrhythmias. The symptoms are often compatible with moderate ventricular dysfunction, such as fatigue and dyspnea. Under specific circumstances acquired diseases may resemble hypertrophic (HCM), restrictive (RCM) or arrhythmic right ventricular cardiomyopathy (ARVC), clinically.

The spontaneous clinical course of acute and chronic disease is unpredictable and depends on the present activity and cause of the ongoing disease (viral infection, inflammation, auto-antibodies, and toxic injury), the extent of the already developed irreversible myocardial damage, and the genetic predisposition of the individual patient. Finally, acquired cardiomyopathies can also occur in patients with pre-existing other heart diseases and thereby occasionally cause additional diagnostic problems.

Since pathophysiological changes of acquired infectious and non-infectious heart muscle diseases occur at a cellular and subcellular level, imaging techniques such as CMR or echocardiography can provide noninvasive tissue characterization but fail in revealing the true underlying causes especially in chronic disease. Confirmation of a specific pathogen or inflammation requires a direct examination of the affected myocardial tissue by endomyocardial biopsy (EMB).

\section{Endomyocardial Biopsy}

Invasive removal of tissue samples by EMBs is always necessary when an exact diagnosis cannot be obtained by other clinical methods and is influencing the following treatment.

This presupposes, in addition to comprehensive information and clear question to the pathologist that the testing laboratory can perform a full diagnosis on the current state of knowledge for the clinically suspected disease. An incomplete diagnosis may provide an incomplete picture of the disease and thus leads to misinterpretations and possibly incorrect treatment decisions.

A basic prerequisite for a clinically relevant biopsy diagnostic is the removal of a sufficient number (more than 10 biopsies) high quality and sufficiently large (2 - 3 $\mathrm{mm}^{2}$ ) tissue samples from different areas of the myocardium. To avoid squeezing artifacts and retain sterility a needle is taken to remove the biopsy from the biopsy forceps. If the sample predominantly contains thrombus, fat or connective tissue, additional samples need to be collected. Apart from specific conditions such as ARVD/ $\mathrm{C}$, in which the characteristic tissue changes mainly occur in certain myocardium areas of the right ventricle, the tissue diagnostic for most questions seems to have a similar sensitivity for left or right ventricular biopsy. To what extent a targeted biopsy of abnormal diagnostic areas of the myocardium, e.g. regional wall motion abnormality, improves the sensitivity of biopsy diagnostic is the subject of ongoing investigations.

The highly complex staged diagnostics of endomyocardial biopsies should be performed only in specialized and certified laboratories with standardized protocols under constant entrainment of internal control samples in all work areas. The constant participation in inter-laboratory surveys for the laboratory testing methods and regular inspections of laboratories by independent monitoring bodies ensure the quality and thus the significance of tissue diagnostics.

The fixation of the biopsies for histological investigations is directly performed in buffered 4\% - 10\% formaldehyde at room temperature. For immunohistological inflammation diagnostics and molecular studies a fixation in RNAlater (from Ambion, USA) is necessary. RNAlater is particularly suitable for the preservation of unstable RNA at room temperature.

For a meaningful tissue diagnosis the myocardium should be optically controlled during sectioning to contain an evaluable proportion of myocardium exceeding $80 \%$ and the tissue samples need to be analyzed completely.

\section{Histological Analysis}

The histological examination of paraffin sections by different staining protocols (H\&E, EvG, PAS, Azan) detects myocardial cell death, scars, fibrosis, disarrays, cardiomyocytes changes, pathological vascular conditions, granulomas, and inflammatory cell differentiation. Storage disorders such as amyloidosis, iron deposits, glycogen and others can be excluded or specified by additional staining, e.g. immunohistochemical differentiation of amyloid subtypes and optionally electron microscopic analyzes (Table 1). The EMB diagnosis of myocarditis was based on histomorphological criteria according to the Dallas classification [4]. Active myocarditis is defined by simultaneous detection of inflammatory infiltrates and present lysis of cardiomyocytes. Active myocarditis or storage diseases are found in 5\% of examined endomyocardial biopsies in histology.

\section{Immunohistochemical Examination on Intramyocardial Inflammation}

Immunohistochemical diagnostics are based on application of specific primary antibodies on cryo-fixed tissue section and following detection of coupled primary antibody by secondary antibody. The secondary antibody is conjugated with an enzyme complex producing a precipitating coloured complex by use of staining solution.

Coloured immunospots are counted digitally by application of established digital imaging analysis software 
Table 1. Overview on current biopsy diagnostic parameters and predictive value for organ-specific and systemic diagnosis.

\begin{tabular}{|c|c|c|c|c|c|}
\hline \multirow[b]{2}{*}{$\begin{array}{l}\text { Section of routine } \\
\text { biopsy diagnostics }\end{array}$} & \multirow[b]{2}{*}{ Diagnostic analysis of } & \multicolumn{2}{|c|}{ Invasive Procedure } & \multirow{2}{*}{$\begin{array}{c}\begin{array}{c}\text { Non-invasive } \\
\text { Procedure }\end{array} \\
\text { Systemic } \\
\text { parameter } \\
\text { (detection in } \\
\text { peripheral blood) }\end{array}$} & \multirow[b]{2}{*}{$\begin{array}{l}\text { Therapeutic } \\
\text { Options }\end{array}$} \\
\hline & & $\begin{array}{l}\text { Focal detection } \\
\text { (biopsy related) }\end{array}$ & $\begin{array}{c}\text { Organ-specific } \\
\text { parameter } \\
\text { (detection in } \\
\text { neighbouring } \\
\text { myocardial tissue) }\end{array}$ & & \\
\hline \multicolumn{6}{|l|}{ Histology } \\
\hline \multicolumn{6}{|l|}{$H \& E$} \\
\hline $\begin{array}{c}\text { Elastica-van-Giesson }(E v G) \\
P A S\end{array}$ & $\begin{array}{l}\text { Active myocarditis, storage } \\
\text { diseases, giant cell } \\
\text { myocarditis, cardiac } \\
\text { sarcoidosis }\end{array}$ & Yes & No & No & $\begin{array}{c}\text { Immunosuppression } \\
\text { (Virus-negative) }\end{array}$ \\
\hline \multicolumn{6}{|l|}{ Azan } \\
\hline Congored & Amyloidosis & Yes & Yes? & Yes? & Transplantation \\
\hline v. Kossa & Deposits of $\mathrm{Ca}^{+}$ & Yes & ? & No & \\
\hline Alcianblue & Acid mucopolysaccharides, odema & Yes & ? & No & \\
\hline Stain on iron & Deposits of $\mathrm{Fe}+$ & Yes & ? & No & \\
\hline SiriusRed & Myocardial fibrosis & Yes & Yes? & No & \\
\hline \multicolumn{6}{|l|}{ Immunohistochemistry } \\
\hline CD3 & Intramyocardial inflammation & Yes & No & No & \\
\hline$L F A 1$ & Intramyocardial inflammation & Yes & No & No & Immunosuppression \\
\hline Mac-1 & Intramyocardial inflammation & Yes & No & No & (Virus-negative) \\
\hline Perforin & Intramyocardial inflammation & Yes & No & No & \\
\hline$H L A-1$ & Tissue activation & Yes & Yes? & No & \\
\hline CD54 & Tissue activation & Yes & Yes? & No & \\
\hline CD106 & Vascular activation & Yes & ? & No & \\
\hline CD31 & Microvessel density & Yes & ? & No & \\
\hline Collagen $1 /$ Collagen 3 & Myocardial fibrosis & Yes & ? & No & \\
\hline $\begin{array}{c}\text { desmosomal proteins for } \\
\text { ARVD diagnostics }\end{array}$ & Suspect on ARVD & Yes & Yes & No & \\
\hline \multicolumn{6}{|l|}{$\begin{array}{l}\text { Molecular Virology/ } \\
\text { Microbiology }\end{array}$} \\
\hline Adenovirus & Viral cardiomyopathy & Yes & No & No & Interferon-Beta \\
\hline Coxsackievirus & Viral cardiomyopathy & Yes & No & No & Interferon-Beta \\
\hline $\begin{array}{c}\text { Erythrovirus (Parvovirus B19) } \\
\text { and viral replication }\end{array}$ & Vascular cardiomyopathy & Yes & Yes? & No & Telbivudine \\
\hline Human Herpesvirus 6 (HHV6) & Immunosuppressive situation & Yes & No & No & \\
\hline $\begin{array}{c}\text { chromosomally integrated } \\
\text { Human Herpesvirus } 6 \text { (ciHHV6) }\end{array}$ & Immunosuppressive situation & Yes & Yes & No & Valganciclovir \\
\hline Epstein-Barr-Virus (EBV) & Immunosuppressive situation & Yes & No & No & \\
\hline Borrelia burgendorferi & Microbial cardiomyopathy & Yes & No & No & Antibiotics \\
\hline Hepatitis $B$ and $C$ & Viral cardiomyopathy? & Yes & No & No & Antiviral \\
\hline
\end{tabular}




\begin{tabular}{|c|c|c|c|c|c|}
\hline$C M V$ & Viral cardiomyopathy? & Yes & No & No & Valganciclovir \\
\hline Other & & Yes & No & No & \\
\hline \multicolumn{6}{|l|}{ Immunology } \\
\hline $\begin{array}{c}\text { Immunofluorescence on } \\
\text { autoantibodies }\end{array}$ & Autoimmune cardiomyopathy & No & No & Yes & Immunoabsorption \\
\hline $\begin{array}{l}\text { Measurement of cardiac } \\
\text { autoantibodies (ELISA) }\end{array}$ & Autoimmune cardiomyopathy & No & No & Yes & Immunoabsorption \\
\hline $\begin{array}{l}\text { Measurement of chemokines and } \\
\text { cytokines in sera/plasma }\end{array}$ & Systemic inflammation & No & No & Yes & Interferon-Beta \\
\hline \multicolumn{6}{|l|}{ Novel biomarkers } \\
\hline Gene expression profiling & Inflammatory and virally-induced & Yes & Yes & Yes? & Silencing RNAs \\
\hline MicroRNA expression profiling & heart muscle diseases & Yes & Yes & Yes* $^{*}$ & Antagomirs \\
\hline Genetic analysis & $\begin{array}{l}\text { Genetically based } \\
\text { cardiomyopathies }\end{array}$ & Yes & Yes & Yes $^{*}$ & \\
\hline
\end{tabular}

?—no sufficient data available, Yes?—detection in other biopsies possible, not sure, Yes — possible detection of specific parameters in body fluids which represent biopsy-located situation.

for calculating area fractions, numbers of immunospots and area of myocardial tissue [5]. The digital imaging system consists of a microscopic unit, a digital camera and supporting analyzing software. Immunohistochemical analysis of intramyocardial inflammation and activation of different tissue fractions (myocytes, capillary) in further biopsies supports the results achieved by histology.

Immunohistochemical analyses are carried out on frozen sections (two EMB) in order to allow detection of elevated inflammatory cell subsets including non-paraffin staining antibodies, e.g. CD3, CD11a (LFA-1), CD11b (MAC-1), CD45R0 (memory or activated lymphocytes), Perforin-positive cytotoxic lymphocytes and increased expression of adhesion molecules CD54 (ICAM), CD106 (VCAM) and HLA-1 as marker for tissue activation.

Perforin-positive, cytotoxic cells were detected in biopsies during acute and chronic phases of infection. Increased number of perforin-positive cells in myocardial tissue is associated with more lesions of cardiomyocytes and poor clinical prognosis of affected patients [6].

Whereas the number of cellular infiltrates (lymphocytes, macrophages) is varying from biopsy to biopsy, the expression of adhesion molecules is globally indicating the tissue activation. Introduction of HLA-1 and CD54 in routine biopsy diagnostics improves prediction of inflammatory processes in myocardium without onsite identification of infiltrative cellular foci [5]. Patients with detectable intramyocardial inflammation are classified as borderline myocarditis due to immunohistochemistry [4]. Inflammatory processes were diagnosed in more than $40 \%$ of all bioptated patients with high predic- tive value for clinical course of these patients [7].

Novel diagnostic markers for cardiomyopathies are the microvessel density (MVD) and the quantitative evaluation of fibrosis. MVD in endomyocardial biopsies is a critical marker in the development of heart muscle diseases. Diagnostics of MVD is performed by the immunohistochemistry of endothelial surface marker CD31. Chronic inflammation or viral infections of myocardium are reducing MVD resulting in malfunction of myocardium and inducing atrophy or hypertrophy of cardiomyocytes.

Myocardial fibrosis detected by CMR is an independent and incremental predictor of mortality and sudden cardiac death in DCM patients [8]. In biopsies the quantitative measurement of intramyocardial fibrosis is performed by immunohistochemistry with Collagen 1 and 3 specific antibodies or staining with Sirius Red and subsequent digital imaging analysis. Correlation of fibrotic areas in myocardial tissue for the risk stratification of acquired cardiomyopathies requires further investigation.

\section{Molecular Virology for Detection of Myocardial Infections}

Microbial genomes are determined, quantified and sequenced using PCR-based methods (Table 1). NestedPCR protocols consisting of two sequentially performed PCR assays, where the amplicon of first assay is the template for second reaction. This procedure is highly sensitive and enables us to detect very low copy numbers of viral genomes (Figure 1). Amplified PCR reactions are separated on agarose gel electrophoresis in ethidium 


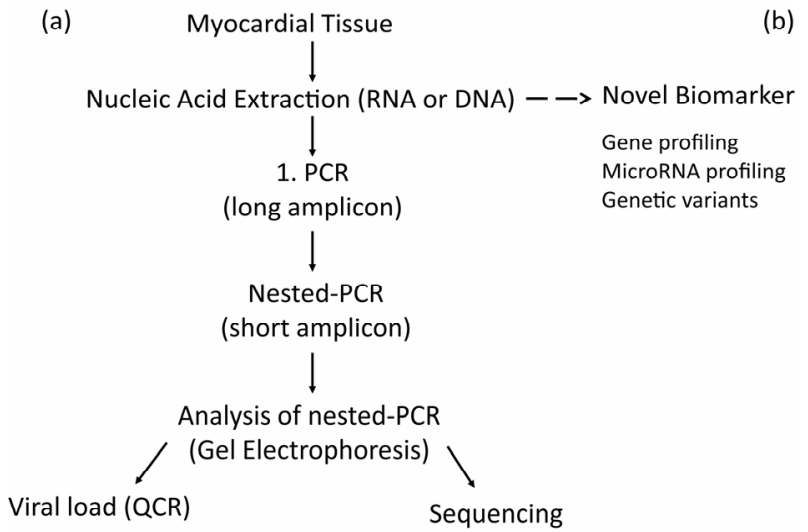

Figure 1. Flowchart of routine diagnostic procedure for detection of cardiotropic viruses (a) and future application of novel biomarker (b) for detection of viral infections, inflammatory diseases or genetic variants predicting development of cardiomyopathies.

bromide containing buffer. This allows the subsequent visualization of generated PCR product by UV fluorescence. All positive PCR reactions are sequenced as quality control, checked by manual alignment and online with NCBI database for confirmation of corresponding virus strains and/or estimation of specific virus subtypes or variants [9].

Depending on the two types of viral nucleic acids the isolation of DNA and RNA is performed in separate extraction procedures. The current viral load monitoring for an effective treatment is performed by quantitative PCR. The transcriptional activity of virus in myocardial tissue or peripheral blood cells will be routinely determined for the two most frequent cardiotropic viruses Erythrovirus and HHV-6 by nested-RT-PCR and QPCR (Figure 1). Patients with active erythroviral infection reported a higher frequency of chest pain, systolic left ventricular ejection fraction and accompanied increase of left ventricular end-diastolic diameter. Because these differences were not associated with myocardial inflammation viral replication seems to be an independent prognostic marker [10].

Human herpesvirus 6 A and B (HHV-6A/B) are possible pathogenetic causes of myocarditis and idiopathiccardiomyopathy subsets [11]. The prevalence of chromosomally integrated HHV-6 (ciHHV-6) is approximately $0.8 \%$ of HHV-6-positive endomyocardial biopsies. Identifying individuals with ciHHV-6 is important because the complete HHV-6 genome is present in every cell in their body [12] and a permanent reactivation of this virus in all tissues is assumed. Detection of ciHHV-6 is only possible by QPCR. Persistent high viral loads of HHV-6 genomes in blood cells or tissues are excluding active infection and confirm ciHHV-6 presence. Elimination of chromosomally integrated virus is impossible but transcriptional activity of ciHHV-6 is reduced under treatment with antiviral drug. Monitoring of viral RNA load is the best indicator for an effective therapy or reactivation of ciHHV-6.

The use of these sensitive techniques to detect the most common cardiotropic viruses (such as enteroviruses, adenoviruses, erythrovirus, human herpesvirus 6, Epstein-Barr virus and in the Far East also hepatitis C) reveals a virus infection in about $50 \%-60 \%$ of patients who are biopsied under the clinical suspicion of myocarditis or DCMI. The clinical significance is clearly demonstrated only for some cardiotropic viruses [13-15].

Current molecular biological workflow for detection of myocardial infection is a combination of qualitative (nPCR) and quantitative detection of viral genomes by nucleic acid isolation systems, thermocycling, gel electrophoresis and real-time QPCR, and subsequent sequencing of generated PCR amplicons by DNA sequencing devices (Table 2).

\section{Indirect Immunofluorescence Testing of Autoimmunity}

Autoimmune cardiomyopathy is an immune-mediated chronic inflammation of the myocardial tissue. Generation of autoantibodies are induced by infection of heart muscle by viruses or by intramyocardial inflammation. The indirect immunofluorescence test is the analytical method of choice for simultaneous screening on different autoantibodies reacting against myocardial tissue. Indirect immunofluorescence assays based on monkey heart tissue slides as a widely similar reference to human tissue. Reaction of patient sera with structural components of presented heart tissue gives first indication of autoantigenic origin (basal membrane, mitochondria and intercalating discs). Cell lines with corresponding virus infection, cells or animal models with overexpression of desired autoantigen were generated. These cultured cells or animal tissue slides were placed as test agents on microscopic slides. Reaction of patient sera with presented reference material corresponds to existing autoantibodies against individual autoantigens [16,17]. The immunological analysis is made by fluorescence microscopy (Table 2).

\section{Immunoassays}

The immune system protects the body from infection by creating and maintaining barriers that prevent bacteria and viruses from entering the body. If a pathogen penetrates these barriers, and gets into the body, the innate immune system is equipped with specialized cells that detect, and often eliminate, the invader before it is able to reproduce, potentially causing serious injury to the host. The innate immune system protects the host by estab- 
Table 2. Analytical methods in current and future diagnostics of cardiomyopathies.

\begin{tabular}{|c|c|c|c|c|c|c|c|c|c|}
\hline \multirow{2}{*}{$\begin{array}{l}\text { Cardiac } \\
\text { disease }\end{array}$} & \multirow{2}{*}{ Subdivision } & \multicolumn{3}{|c|}{ Standard Biopsy Diagnostics } & \multirow{2}{*}{$\begin{array}{c}\text { Immunology, } \\
\text { indirect } \\
\text { immunofluorescence }\end{array}$} & \multirow{2}{*}{$\begin{array}{c}\text { New } \\
\text { Biomarker } \\
\text { Biopsy }\end{array}$} & \multirow{2}{*}{$\begin{array}{c}\text { Biopsy or } \\
\text { PBMC } \\
\text { Genetics }\end{array}$} & \multirow{2}{*}{ 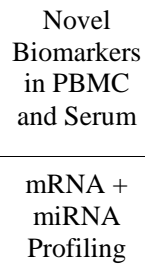 } & \multirow{2}{*}{$\begin{array}{l}\text { Therapeutic } \\
\text { Options }\end{array}$} \\
\hline & & Histology & $\begin{array}{l}\text { Immunhisto- } \\
\text { chemistry }\end{array}$ & $\begin{array}{l}\text { Molecular } \\
\text { Biology }\end{array}$ & & & & & \\
\hline $\begin{array}{c}\text { Dilated } \\
\text { Cardiomyopathy }\end{array}$ & & + & & & & + & + & + & $\begin{array}{l}\text { Heart failure } \\
\text { therapy }\end{array}$ \\
\hline $\begin{array}{c}\text { Dilated } \\
\text { Cardiomyopathy } \\
\text { with } \\
\text { inflammation }\end{array}$ & & + & + & & & + & - & + & $\begin{array}{l}\text { Immune } \\
\text { suppression }\end{array}$ \\
\hline $\begin{array}{l}\text { Autoimmune } \\
\text { Cardiomyopathy }\end{array}$ & & + & + & & + & & - & & \\
\hline $\begin{array}{c}\text { Acute } \\
\text { Myocarditis }\end{array}$ & & + & + & & & + & - & + & $\begin{array}{l}\text { Immune } \\
\text { suppression }\end{array}$ \\
\hline $\begin{array}{l}\text { Borderline } \\
\text { Myocarditis }\end{array}$ & & + & + & & & + & - & + & $\begin{array}{c}\text { Immune } \\
\text { suppression }\end{array}$ \\
\hline $\begin{array}{l}\text { Idiopathic Giant } \\
\text { Cell Myocarditis }\end{array}$ & & + & & & & + & - & + & $\begin{array}{l}\text { Immune } \\
\text { suppression }\end{array}$ \\
\hline \multirow{5}{*}{$\begin{array}{l}\text { Virus-induced } \\
\text { Cardiomyopathy }\end{array}$} & Adenovirus & & & + & + & + & - & + & $\begin{array}{l}\text { Antiviral } \\
\text { therapy }\end{array}$ \\
\hline & $\begin{array}{c}\text { Human } \\
\text { Herpesvirus } 6\end{array}$ & & + & + & + & + & - & + & $\begin{array}{l}\text { Antiviral } \\
\text { therapy }\end{array}$ \\
\hline & $\begin{array}{c}\text { Erythrovirus } \\
\text { (Parvovirus B19) }\end{array}$ & & & + & + & + & - & + & $\begin{array}{l}\text { Antiviral } \\
\text { therapy }\end{array}$ \\
\hline & $\begin{array}{l}\text { Coxsackievirus } \\
\text { persistent }\end{array}$ & & & + & + & + & - & + & $\begin{array}{l}\text { Antiviral } \\
\text { therapy }\end{array}$ \\
\hline & $\begin{array}{l}\text { Coxsackievirus } \\
\text { spontaneously } \\
\text { eliminated }\end{array}$ & & & + & & + & - & + & $\begin{array}{l}\text { No therapy } \\
\text { necessary }\end{array}$ \\
\hline $\begin{array}{l}\text { Analytical } \\
\text { Methods }\end{array}$ & & \multicolumn{2}{|c|}{$\begin{array}{l}\text { Light and Fluorescence } \\
\text { Microscopy and digital } \\
\text { imaging analysis }\end{array}$} & $\begin{array}{c}\text { nPCR + } \\
\text { QPCR + } \\
\text { Sequencing }\end{array}$ & $\begin{array}{c}\text { Fluorescence } \\
\text { Microscopy, } \\
\text { Multiplex-ELISA }\end{array}$ & $\begin{array}{l}\text { QPCR } \\
\text { Array }\end{array}$ & $\begin{array}{l}\text { Sequencing, } \\
\text { SNP array, } \\
\text { NGS }\end{array}$ & $\begin{array}{l}\text { QPCR } \\
\text { Array }\end{array}$ & \\
\hline
\end{tabular}

Grey-currently applied methods in routine diagnostics of endoymocardial biopsies, NGS-next-generation-sequencing, nPCR-nested-PCR, QPCR-quantitative PCR, PBMC-peripheral blood mononuclear cells, SNP-single nucleotide polymorphism

lishing humoral, chemical and cellular barriers to infection. Inflammatory response is produced by chemical factors including specialized chemical mediators, called cytokines. Cytokine levels in peripheral blood correspond to systemic situation in patients initiated by various, but often global factors like infections or inflammatory processes. Cytokines or chemokines are estimated in blood serum for characterization of present immune response. High level of interferon-beta in serum results in spontaneous elimination of enterovirus from myocardial tissue and is associated with reduced long term mortality in cardiac patients [15].

Immunoassays on cardiac autoantibodies [17] or cellular hormones like adiponectin [18] are good tools for monitoring clinical cause of cardiomyopathies and sup- port biopsy diagnostics. Limitations are the availability of corresponding assays for multiple cardiac autoantigens. For the quantitative determination of autoantibodies or antibodies against infectious agents, cells, tissue sections or purified, biochemically characterized substances are used as antigen substrates.

Introduction of multiplexing technologies allows the simultaneous measurement of up to 500 analytes in a single patient sample. Multiplex-ELISA is using fluorescent microparticles (beads) with immobilized antibodies against different cytokines, chemokines or other antigens. The incubation of these beads with patients serum results in binding of specific antigens and subsequent detection by a second antibody which is labeled with a second dye. This approach allows also the measurement of multiple 
cardiac autoantibodies in one assay. Final analysis of this microparticle based test is performed by dual-color flow cytometry, discriminating different colors and sizes of applied beads. Novel set-ups are using final fluorescence microscopic analysis, placing beads by sedimentation or magnetic placement at the bottom of reaction vessels for digital imaging analysis $[16,19]$.

Immunological set-up in cardiology consists of manual or automated performance of ELISA detection of antigens of interest and a full-automated analysis by flow cytometric or microscopic principle (Table 2).

\section{Profiling Technologies for miRNAs or Gene Expression-The Way to Organ-Specific and Systemic Diagnosis}

Positive diagnostic findings in examined biopsies are confirming the myocardial condition, but negative results will not exclude infections or intramyocardial inflammation. Increasing number of biopsies will reduce biopsy-depending sampling error, but could never overcome it completely. This fact is indicating the need of global and stable biomarkers to identify disease entities in the effected organ preventing and overcoming sampling error (Figure 2).

First investigations indicate that deregulation of myocardial gene expression is not limited to focal biopsy area, and therefore allows the identification of specific disease situations of the examined patient analyzing neighboring biopsies [20]. It becomes difficult to diagnose complex diseases by one parameter. Current diagnostic biomarker panels are consisting of a few deregulated genes. Viral infections or massive infiltration of inflammatory cells in myocardium could be diagnosed in neighboring tissue samples without histological confirmation of these agents. We identified a gene pattern differentiating virally-induced or inflammatory cardiomyopathies like active myocarditis or giant cell myocarditis from inflammation-free or non-infected myocardium. Such disease specific profiles will change during effective treatment and thereby could also be applied for therapy monitoring.

miRNAs are small non-coding regulatory molecules (17 - $24 \mathrm{nt})$ and were recently identified as important regulators of genetic expression in myocardial tissue $[10$,

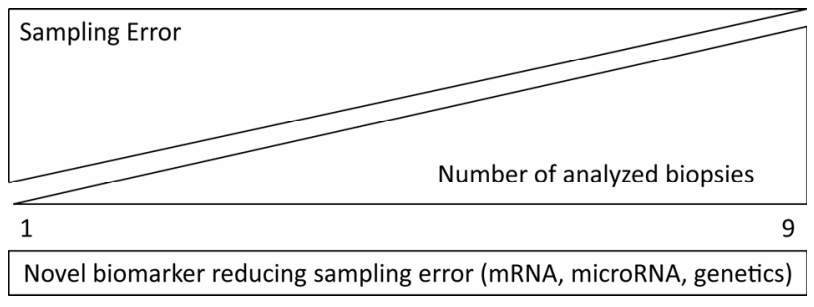

Figure 2. Biopsy-independent novel biomarkers for reduction of sampling error at a limited number of biopsies.
21]. They modulate gene expression by enhanced degradation of protein-coding mRNAs or sequestration from the translational apparatus. The role of miRNAs in physiologic and pathologic processes and the capability to correlate expression changes with disease states highlights their value as novel molecular biomarkers [22]. Currently available miRNA profiles allow the identification of preceding cardiotropic infection even in PCRnegative biopsies [10]. The clinical course of this patient is predictable at the point of primary biopsy and a disease-directed therapy could be initiated immediately to prevent myocardial injuries.

miRNAs have been demonstrated to play crucial roles in the etiology of a variety of common human diseases. They are involved in intra- and intercellular communication. miRNAs were detected not only in human tissue but also in serum or plasma influencing systemic response on organ-specific alterations. These findings emphasize the potential of circulating miRNAs as stable blood-based markers for the detection of cardiomyopathies [23]. The investigation of miRNA expression profiles in body fluids opens a completely new diagnostic approach to detect and characterize focal diseases by systemic markers with an easily taken and abundant sample. The detection of bladder cancer by determination of miRNA profiles in urine as an example for the development of non-invasive tests to detect human diseases is a tremendous benefit to both patients and healthcare systems $[24,25]$.

Although the incidence of annual new cases suffering of cardiomyopathies is more than 25,000, only about 5000 patients are bioptated per year in Germany. Application of miRNA profiling in blood samples is an option to identify more patients with severe forms of cardiomyopathies before visiting a catheter lab. This blood based miRNA screening could reduce the disproportion of under diagnosed cardiac patients by strong indication for an endomyocardial biopsy to diagnose the origin of heart muscle disease.

Quantitative PCR for gene expression or miRNAs is the method of choice for profiling assays by high sensitivity and broad dynamic range of detection. Low density QPCR arrays or microplate based set-ups are convenient for diagnostic use of expression panels for up to 50 analytical parameters (Table 2) [26].

\section{Proof of Disease-Related Gene Mutations for Cardiomyopathies}

Current guidelines recommend genetic screening (evidence level A) for ARVD/C, HCM and DCM with conduction abnormalities or extra cardiac manifestations [27]. Although for many cardiomyopathies a genetic predisposition is shown, the genetic analysis is costly and time consuming yet therapeutically relevant for only a 
few diseases. Next generation sequencing (NGS) technologies will enable each lab to perform genetic testing for a low price but the interpretation of genetic data is still requesting great expertise. Now NGS is entering the diagnostic level. Advantage of de novo sequencing of all cardiac genes is the identification of temporary unknown mutations in patients with expressed heart failure problems.

Nevertheless recent studies identified a massive overpresentation of previously described cardiomyopathyrelated genetic variants in a healthy control cohort with genotype prevalence thousand fold higher than in diseased patients [28]. This finding makes genetic testing without prior clinic-diagnostically definition questionable. Only an endomyocardial biopsy supported genetic study could identify genetic markers which are associated with occurrence of genetic cardiomyopathies excluding myocardial inflammation or microbial infections as reason for preceding heart muscle disease.

Drawback of all genetic testing is the trust on imaging techniques as primary cardiological diagnostics. A differential diagnosis of infiltrative processes of myocardium or wall hypertrophy in acute inflammatory diseases caused by oedema is requested besides a first documented myocardial wall hypertrophy or restrictive filling pattern in addition to the usually genetically, primary hypertrophic and restrictive cardiomyopathies. In biopsies of patients suspicious for HCM or ARVD were often found storage diseases, massive infiltration of inflammatory cells or viral genomes undetectable by echocardiography, CMR or CT. By additional laboratory and cardiac enzyme tests or tissue biopsies, it is usually possible to make a specific diagnosis. Morbus Fabry documented by measuring the alpha-galactosidase activity of leukocytes is well treated by enzyme replacement therapy. In the case of histologically diagnosed amyloidosis immunohistological classification of the corresponding subtype is required, for example to distinguish an age-related from a genetically determined ATTR form that requires family counseling [29].

In general, genetic testing is unable to detect viral infections or inflammation in myocardium. Nevertheless the enormous power of NGS to read out millions of sequences fragments in a very short period [30] will allow the parallel identification of pathological mutations in genomic DNA and the included microbial genomes in the same patient sample.

Routineously applied methods for confirmation of existing disease-relevant mutations are direct sequencing of small genomic regions harbouring the single nucleotide polymorphism (SNP) or PCR based detection of individual mutations, if the distance between neighbouring mutated site is too far for sequencing. Diagnostic sets of up to 50 SNP PCRs could be placed on low density ar- rays and allow the simultaneous analysis of multiple gene aberations in on assay [31] (Table 2).

\section{Diagnostic-Based Treatment Decisions}

Since a significant proportion of acute myocardial disease heals spontaneously and associated arrhythmias may regress completely, mechanical circulatory support and implantation of permanent pacemakers or automatic defibrillators (ICD's) should be only used if it is not possible to stabilize the patients by a symptomatic therapy. These measures are often the only therapeutic option for genetic cardiomyopathies.

Develop patients a rapidly progressive pump dysfunction despite optimal medical treatment, the prognosis can often be improved by rapid and sustained cause-oriented treatment. In acute heart failure, biopsy-based information is mandatory to recognize virus negative inflammation that requires immediate and tailored immunosuppression in order to reduce early mortality and improve long-term outcome. An immediate biopsy diagnostics with an immediately following initiation of therapy is particularly indicated in the eosinophil, the necrotic and giant cell myocarditis, which often respond well to early immunosuppressive treatment while untreated a very high mortality occurs (Table 2) [32,33].

In chronic inflammation, virus-negative patients with post-infectious or auto-immune inflammatory processes responded well to immunosuppression in early clinical trials. Virus-positive patients do not improve or even deteriorate upon anti-inflammatory treatment [34].

Clinical investigation in the last ten years revealed at least one therapeutic option for the four most important cardiotropic viruses (adenovirus, enterovirus, erythrovirus, HHV-6) with different grades of efficiency (Table 1). Myocardial injury is also occurring under optimal heart failure therapy progressive due to persistence of cardiotropic viruses. For anti-viral treatment currently two approaches are existing: immunomodulation supporting intrinsic immune response or antiviral drugs affecting life cycle of corresponding virus. Patients with chronic heart failure due to persistent enterovirus and adenovirus infections of the myocardium responded well to a six months' interferon-beta (IFN- $\beta$ ) course, but have untreated a really poor prognosis $[15,35]$. Complete elimination of viral genome was proven by follow-up biopsies taken three month after termination of the antiviral therapy [15]. Virus clearance was paralleled by an improvement of mean left ventricular function, a decrease in ventricular size, and amelioration of heart failure symptoms. Other viruses, e.g. parvovirus B19 or human herpesvirus 6 , respond less well upon IFN- $\beta$ treatment with respect to virus clearance. Despite incomplete virus clearance, these patients improved clinically following reduction of 
virus load and of endothelial function [36].

Erythrovirus (Parvovirus B19) is the most frequent cardiotropic virus. In $10 \%$ of all erythrovirus DNA positive patients an active replication is detectable by measurement of viral RNA [10]. Clinical symptoms of these patients are improving shortly after initialization of antiviral treatment by replication inhibitor Telbivudine (Table 1).

Valcyte is an effective antiviral drug for treatment of cytomegalovirus (CMV) infections in immunocompromised transplant patients. CMV is a member of herpesvirus family. Less than $1 \%$ of all bioptated patients are harboring ciHHV-6. This life-long infection is characterized by permanent generation of virus and resulting in a clinical situation similar to immunosuppression [10]. The treatment with Valcyte is not influencing the load of viral DNA in these patients but is reducing or eliminating the viral RNA hindering de novo synthesis of virus particles. Patient's general condition is improving by overcoming the immunocompromised situation. Valcyte should be an effective drug for conventional HHV-6 too, but corresponding trials are still missing due to low viral titers in myocardium and few patients with suspected HHV-6 myocarditis.

The efficiency of antiviral or immunosuppressive therapy may be reviewed only by a control biopsy. The absence of inflammatory markers, elimination of treated virus or at minimum a reduction of viral load in myocardium is a good predictor of successful treatment. Imaging techniques and physical activity testing are confirming clinical improvement.

Modern therapeutic options are based on inhibition of single gene expression by silencing RNAs or oligonucleotide-based therapies [37]. Blocking of one specific miRNA or miRNA groups is more effective by regulation of whole gene cascades or multiple gene families [38]. Current application of silencing mRNAs, antisense oligonucleotides or miRNA blocking molecules (antagomirs) are subject of intensive research but not available yet for routine drug treatment.

Novel biomarkers in myocardial tissue or peripheral blood for therapy monitoring will change their profile during therapy indicating the change of molecular marker on focal or systemic level.

\section{Conclusions}

General guidelines for diagnosis, treatment and corresponding quality analyses are missing for various, especially acquired cardiomyopathies [39]. The unequivocal diagnosis and thereupon based specific treatment in these patients is often only possible by direct examination of the myocardial tissue or special supplementary examinations, since the pathophysiological changes in these diseases occur at the cellular level. In this regard, therapy guiding diagnostics must be standardized and controlled.

In order to recognize whether an infectious disease may hide behind uncharacteristic cardiac symptoms and consequently proof a myocarditis unambiguously poses an important clinical challenge. A reliable diagnostic differentiation between virus-positive or virus-negative myocarditis and thereby indication of the infectious state needs to be accomplished to allow successful administration of a pathogen-tailored treatment strategy. This approach cannot be reached by routine clinical diagnosis but demands biopsy-based information with complete histological, immunohistochemical, and molecular workup of tissue samples. Although EMB diagnostics are revealing only an extract of heart's current situation, this is still the gold standard for final confirmation of causative reasons of cardiomyopathies. This fact is indicating the need of global organ-specific or systemic markers which are disclosing the condition of the entire heart and therefore overcoming the sampling error.

Beside genetic markers for a limited subgroup of cardiomyopathies, novel biomarkers as miRNA and gene expression profiling are introduced in molecular examination of EMB presenting a global picture of heart muscle and overcoming the limitation of biopsy-focused diagnostics. These profiling approaches will improve the diagnosis of heart muscle disease and the monitoring of initiated therapeutic approaches in treatment of different forms of virally-induced or inflammatory cardiomyopathies by minimizing the sampling error. Measurement of disease-related miRNA profiles in peripheral blood could facilitate identification of currently undiagnosed cardiac patients by strong indication for endomyocardial biopsy examination.

\section{Acknowledgements}

Development of some diagnostic procedures and treatment strategies were supported by grants of the German Research Foundation (DFG), Transregional Collaborative Research Centre "Inflammatory CardiomyopathyMolecular Pathogenesis and Therapy" (SFB TR19, Z1), and two grants of the Federal Ministry of Education and Research (BMBF, Germany) for KMU innovative program (No.616 0315296, 0316141A).

\section{REFERENCES}

[1] P. P. Liu and H.-P. Schultheiss, "Myocarditis,” In: Baunwalded, Ed., Heart Disease, 8th Edition, W. B. Saunders Co., Philadelphia, 2008, pp. 1775-1792.

[2] H.-P. Schultheiss, U. Kühl and L. T. Cooper, "The Management of Myocarditis,” European Heart Journal, Vol. 33, No. 21, 2011, pp. 2616-2625.

[3] L. T. Cooper, K. L. Baughman, A. M. Feldman, et al., "The Role of Endomyocardial Biopsy in the Management 
of Cardiovascular Disease,” European Heart Journal, Vol. 28, 2007, pp. 3076-3093.

[4] H. T. Aretz, "Myocarditis: The Dallas Criteria," Human Pathology, Vol. 18, No. 6, 1987, pp. 619-624. doi:10.1016/S0046-8177(87)80363-5

[5] M. Noutsias, M. Pauschinger, K. Ostermann, F. Escher, J. H. Blohm, H.-P. Schultheiss and U. Kühl, "Digital Image Analysis System for the Quantification of Infiltrates and Cell Adhesion Molecules in Inflammatory Cardiomyopathy," Medical Science Monitor, Vol. 8, No. 5, 2002, pp. 59-71.

[6] J. C. Silverio, L. M. de-Oliveira-Pinto, A. A. da Silva, G. M. de Oliveira and J. Lannes-Vieira, "Perforin-Expressing Cytotoxic Cells Contribute to Chronic Cardiomyopathy in Trypanosomacruzi Infection," International Journal of Experimental Pathology, Vol. 91, No. 1, 2010, pp. 72-86. doi:10.1111/j.1365-2613.2009.00670.X

[7] I. Kindermann, M. Kindermann, R. Kandolf, K. Klingel, B. Bültmann, T. Müller, A. Lindinger and M. Böhm, "Predictors of Outcome in Patients with Suspected Myocarditis,” Circulation, Vol. 118, No. 6, 2008,pp. 639-648. doi:10.1161/CIRCULATIONAHA.108.769489

[8] A. Gulati, A. Jabbour, T. F. Ismail, K. Guha, J. Khwaja, S. Raza, K. Morarji, T. D. Brown, N. A. Ismail, M. R. Dweck, E. Di Pietro, M. Roughton, R. Wage, Y. Daryani, R. O’Hanlon, M. N. Sheppard, F. Alpendurada, A. R. Lyon, S. A. Cook, M. R. Cowie, R. G. Assomull, D. J. Pennell and S. K. Prasad, "Association of Fibrosis with Mortality and Sudden Cardiac Death in Patients with Nonischemic Dilated Cardiomyopathy,” JAMA, Vol. 309, No. 9, 2013, pp. 896-908. doi:10.1001/jama.2013.1363

[9] U. Kühl, D. Lassner, M. Pauschinger, U. M. Gross, B. Seeberg, M. Noutsias, W. Poller and H.-P. Schultheiss, "Prevalence of Erythrovirus Genotypes in the Myocardium of Patients with Dilated Cardiomyopathy," Journal of Medical Virology, Vol. 80, No. 8, 2008, pp. 12431251. doi:10.1002/jmv.21187

[10] U. Kühl, M. Rohde, D. Lassner, U. M. Gross, F. Escher and H. P. Schultheiss, "miRNA as Activity Markers in Parvo B19 Associated Heart Disease,” Herz, Vol. 37, No. 6, 2012, pp. 637-643. doi:10.1007/s00059-012-3656-3

[11] U. Kuhl, M. Pauschinger, M. Noutsias, et al., "High Prevalence of Viral Genomes and Multiple Viral Infections in the Myocardium of Adults with 'Idiopathic' Left Ventricular Dysfunction,” Circulation, Vol. 111, 2005, pp. 887-893. doi:10.1161/01.CIR.0000155616.07901.35

[12] P. E. Pellett, D. V. Ablashi, P. F. Ambros, et al., "Chromosomally Integrated Human Herpesvirus 6: Questions and Answers," Reviews in Medical Virology, Vol. 22, No. 3, 2012, pp. 144-155. doi:10.1002/rmv.715

[13] C. T. Bock, K. Klingel and R. Kandolf, "Human Parvovirus B19-Associated Myocarditis,” The New England Journal of Medicine, Vol. 362, No. 13, 2010, pp. 12481249.

[14] A. L. Caforio, F. Calabrese, A. Angelini, et al., "A Prospective Study of Biopsy-Proven Myocarditis: Prognostic Relevance of Clinical and Aetiopathogenetic Features at Diagnosis,” European Heart Journal, Vol. 28, No. 11, 2007, pp. 1326-1333. doi:10.1093/eurheartj/ehm076
[15] U. Kühl, D. Lassner, J. von Schlippenbach, W. Poller and H. P. Schultheiss "Interferon-Beta Improves Survival in Enterovirus-Associated Cardiomyopathy," Journal of the American College of Cardiology, Vol. 60, No. 14, 2012, pp. 1295-1296. doi:10.1016/j.jacc.2012.06.026

[16] A. Willitzki, R. Hiemann, V. Peters, U. Sack, P. Schierack, S. Rödiger, U. Anderer, K. Conrad, D. P. Bogdanos, D. Reinhold and D. Roggenbuck, "New Platform Technology for Comprehensive Serological Diagnostics of Autoimmune Diseases," Clinical and Developmental Immunology, Vol. 2012, 2012, Article ID: 284740.

[17] N. Deubner, D. Berliner, A. Schlipp, G. Gelbrich, A. L. Caforio, S. B. Felix, M. Fu, H. Katus, C. E. Angermann, M. J. Lohse, G. Ertl, S. Störk, R. Jahns, Etiology, Titre-Course and Survival-Study Group, "Cardiac Beta1Adrenoceptor Autoantibodies in Human Heart Disease: Rationale and Design of the Etiology, Titre-Course, and Survival (ETiCS) Study," European Journal of Heart Failure, Vol. 12, No. 7, 2010, pp. 753-762. doi:10.1093/eurjhf/hfq072

[18] C. Skurk, F. Wittchen, L. Suckau, H. Witt, M. Noutsias, H. Fechner, H.-P. Schultheiss and W. Poller, "Description of a Local Cardiac Adiponectin System and Its Deregulation in Dilated Cardiomyopathy," European Heart Journal, Vol. 29, No. 9, 2008, pp. 1168-1180. doi:10.1093/eurheartj/ehn136

[19] K. L. Kellar, R. R. Kalwar, K. A. Dubois, D. Crouse, W. D. Chafin and B. E. Kane, "Multiplexed Fluorescent Bead-Based Immunoassays for Quantitation of Human Cytokines in Serum and Culture Supernatants," Cytometry, Vol. 45, No. 1, 2001, pp. 27-36.

doi:10.1002/1097-0320(20010901)45:1<27::AID-CYTO1 141>3.0.CO;2-I

[20] F. Wittchen, L. Suckau, H. Witt,C. Skurk, D. Lassner, H. Fechner, I. Sipo, U. Ungethüm, P. Ruiz, M. Pauschinger, C. Tschope, U. Rauch U, Kühl, H.-P. Schultheiss and W. Poller, "Genomic Expression Profiling of Human Inflammatory Cardiomyopathy (DCMi) Suggests Novel Therapeutic Targets,” European Heart Journal, Vol. 85, No. 3, 2007, pp. 257-271. doi:10.1007/s00109-006-0122-9

[21] S. V. Naga Prasad, Z. H. Duan, M. K. Gupta, et al., "Unique microRNA Profile in End-Stage Heart Failure Indicates Alterations in Specific Cardiovascular Signaling Networks," The Journal of Biological Chemistry, Vol. 284, 2009, pp. 27487-27499. doi:10.1074/jbc.M109.036541

[22] D. Baek, J. Villen, C. Shin, F. D. Camargo, S. P. Gygi and D. P. Bartel, "The Impact of microRNAs on Protein Output,” Nature, Vol. 4355, No. 7209, 2008, pp. 64-71. doi:10.1038/nature07242

[23] P. S. Mitchell, R. K. Parkin, et al., "Circulating microRNAs as Stable Blood-Based Markers for Cancer Detection,” PNAS, Vol. 105, 2008, pp. 10513-10518.

[24] G. Wang, E. S. Chan, B. C. Kwan, P. K. Li, S. K. Yip, C. C. Szeto and C. F. Ng, "Expression of miRNAs in the Urine of Patients with Bladder Cancer," Clinical Genitourinary Cancer, Vol. 10, No. 2, 2012, pp. 106-113. doi:10.1016/j.clgc.2012.01.001 
[25] P. Puerta-Gil, R. Garcia-Baquero, A. Y. Jia, S. Ocana, M. Alvarez-Mugica, J. L. Alvarez-Ossorio, C. Cordon-Cardo, F. Cava and M. Sanchez-Carbayo, "miR-143, miR-222, and miR-452 Are Useful as Tumor Stratification and Noninvasive Diagnostic Biomarkers for Bladder Cancer," American Journal of Pathology, Vol. 180, No. 5, 2012, pp. 1808-1815. doi:10.1016/j.ajpath.2012.01.034

[26] E. V. Grigorenko, E. Ortenberg, J. Hurley, A. Bond and K. Munnelly, "miRNA Profiling on High-Throughput OpenArray ${ }^{\mathrm{TM}}$ System,” Methods in Molecular Biology, Vol. 676, 2011, pp. 101-110. doi:10.1007/978-1-60761-863-8_8

[27] R. E. Hershberger, J. Lindenfeld, L. Mestroni, C. E. Seidman, M. R. Taylor and J. A. Towbin, "Genetic Evaluation of Cardiomyopathy: A Heart Failure Society of America Practice Guideline,” Journal of Cardiac Failure, Vol. 15, No. 2, 2009, pp. 83-97. doi:10.1016/j.cardfail.2009.01.006

[28] C. Andreasen, J. B. Nielsen, L. Refsgaard, A. G. Holst, A. H. Christensen, L. Andreasen, A. Sajadieh, S. Haunsø, J. H. Svendsen and M. S. Olesen, "New Population-Based Exome Data Are Questioning the Pathogenicity of Previously Cardiomyopathy-Associated Genetic Variants," European Journal of Human Genetics, 2013. doi:10.1038/ejhg.2012.283

[29] D. Lassner, M. Rohde, U. M. Gross, F. Escher, H. P. Schultheiss, R. P. Linke and U. Kühl, "Classification of Four Chemically Different Amyloid Types in Routine Endomyocardial Biopsies by Advanced Immunohistochemistry,” Amyloid, Vol. 18, Suppl. 1, 2011, pp. 76-78. doi:10.3109/13506129.2011.574354027

[30] D. A. Wheeler, M. Srinivasan, M. Egholm, et al., "The Complete Genome of an Individual by Massively Parallel DNA Sequencing,” Nature, Vol. 452, No. 7189. 2008, pp. 872-876. doi:10.1038/nature06884

[31] K. Hopp, K. Weber, D. Bellissimo, S. T. Johnson and B. Pietz, "High-Throughput Red Blood Cell Antigen Genotyping Using a Nanofluidic Real-Time Polymerase Chain Reaction Platform,” Transfusion, Vol. 50, No. 1, 2010, pp. 40-46. doi:10.1111/j.1537-2995.2009.02377.x

[32] L. J. Cooper, J. M. Hare, H. D. Tazelaar, et al., "Usefulness of Immunosupp. Ression for Giant Cell Myocarditis," American Journal of Cardiology, Vol. 102, 2008, pp. 1535-1539. doi:10.1016/j.amjcard.2008.07.041

[33] A. Frustaci, C. Chimenti, F. Calabrese, et al., "Immunosupp. Ressive Therapy for Active Lymphocytic Myocarditis: Virological and Immunologic Profile of Responders versus Nonresponders,” Circulation, Vol. 107, 2003, pp. 857-863. doi:10.1161/01.CIR.0000048147.15962.31

[34] A. Frustaci, M. A. Russo and C. Chimenti, "Randomized Study on the Efficacy of Immunosupp. Ressive Therapy in Patients with Virus-Negative Inflammatory Cardiomyopathy: The TIMIC Study," European Heart Journal, Vol. 30, No. 16, 2009, pp. 1995-2002. doi:10.1093/eurheartj/ehp249

[35] U. Kuhl, M. Pauschinger, P. L. Schwimmbeck, B. Seeberg, C. Lober and M. Noutsias, "Interferon-Beta Treatment Eliminates Cardiotropic Viruses and Improves Left Ventricular Function in Patients with Myocardial Persistence of Viral Genomes and Left Ventricular Dysfunction,” Circulation, Vol. 107, No. 22, 2003, pp. 27932798. doi:10.1161/01.CIR.0000072766.67150.51

[36] C. Schmidt-Lucke, F. Spillmann, T. Bock, U. Kühl, S. Van Linthout, H.-P. Schultheiss and C. Tschöpe "Interferon Beta Modulates Endothelial Damage in Patients with Cardiac Persistence of Human Parvovirus b19 Infection,” The Journal of Infectious Diseases, Vol. 201 No. 6, 2010, pp. 936-945. doi:10.1086/650700

[37] T. M. Wheeler, A. J. Leger, S. K. Pandey, A. R. MacLeod, M. Nakamori, S. H. Cheng, B. M. Wentworth, C. F. Bennett and C. A. Thornton, "Targeting Nuclear RNA for in Vivo Correction of Myotonic Dystrophy,” Nature, Vol. 488, No. 7409, 2012, pp. 111-115. doi:10.1038/nature11362

[38] T. G. Hullinger, R. L. Montgomery, A. G. Seto, B. A. Dickinson, et al., "Inhibition of miR-15 Protects against Cardiac Ischemic Injury,” Circulation Research, Vol. 110, No. 1, 2012, pp. 71-81. doi:10.1161/CIRCRESAHA.111.244442

[39] L. T. Cooper, K. L. Baughman, A. M. Feldman, A. Frustaci, M. Jessup, U. Kuhl, G. N. Levine, J. Narula, R. C. Starling, J. Towbin and R. Virmani, American Heart Association, American College of Cardiology, European Society of Cardiology, Heart Failure Society of America and Heart Failure Association of the European Society of Cardiology, "The Role of Endomyocardial Biopsy in the Management of Cardiovascular Disease: A Scientific Statement from the American Heart Association, the American College of Cardiology, and the European Society of Cardiology. Endorsed by the Heart Failure Society of America and the Heart Failure Association of the European Society of Cardiology," Journal of the American College of Cardiology, Vol. 50, No. 19, 2007, pp. 1914-1931. doi:10.1016/j.jacc.2007.09.008 


\section{Abbreviations}

ciHHV-6 = chromosomally integrated human herpesvirus 6 ,

$\mathrm{CMR}=$ cardiac magnetic resonance,

DCM = Dilated Cardiomyopathy,

$\mathrm{EMB}=$ endomyocardial biopsy,

ESC = European Society of Cardiology,
miRNA $=$ microRNA,

MVD = microvessel density,

NGS = next generation sequencing,

PBMC = peripheral blood mononuclear cells,

$\mathrm{PCR}=$ polymerase chain reaction,

$\mathrm{QPCR}=$ quantitative $\mathrm{PCR}$,

SNP = single nucleotide polymorphism. 